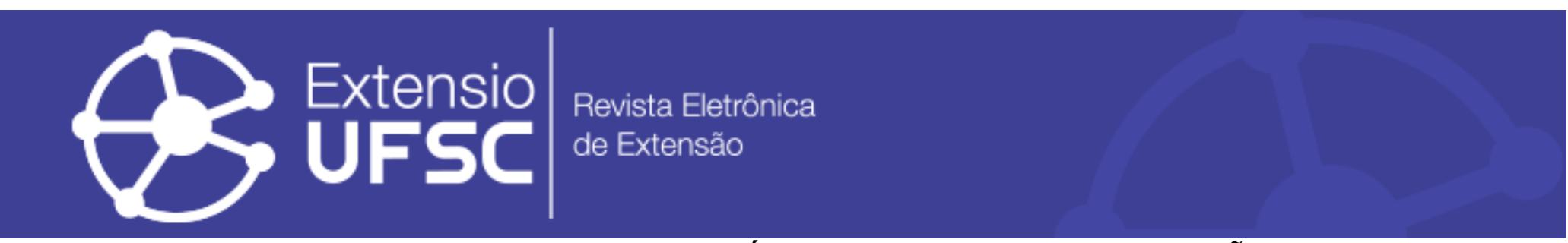

\title{
ESTUDO DA MARATONA DE CÁLCULO COMO INTERVENÇÃO PARA O ELEVADO ÍNDICE DE RETENÇÃO EM CÁLCULO I
}

\author{
Leonardo Moreto Elias \\ Universidade Federal de Santa Catarina \\ leonardo.elias@ufsc.br \\ Luana Aparecida Gomes \\ Universidade Federal de Santa Catarina \\ luana00gomes@gmail.com
}

Resumo

As taxas de retenção em Cálculo Diferencial e Integral são um problema do ensino superior que se destaca diante de outras disciplinas da graduação e prejudica a formação de profissionais das exatas. Nesse ínterim, com o objetivo de incentivar o seu estudo, criou-se o projeto Maratona de Cálculo, uma competição matemática em que estudantes se desafiam na resolução de derivadas de funções de uma variável. Este artigo apresenta uma análise quali-quantitativa acerca da implementação do projeto desenvolvido entre 2016 e 2019 na Universidade Federal de Santa Catarina, Centro Tecnológico de Joinville. Para tanto, foram realizadas análises a partir do formulário de inscrição do evento, aplicação de um questionário para matriculados em disciplinas relacionadas a Cálculo e entrevistas com participantes. Por fim, o projeto mostrou-se eficaz no desenvolvimento lógico e de competências dos estudantes, além de contribuir para a criação de uma universidade mais saudável.

Palavras-chave: Cálculo Diferencial e Integral; Jogos Matemáticos; Maratona de Cálculo.

\section{STUDY OF THE CALCULUS MARATHON AS AN INTERVENTIVE MEASURE FOR THE HIGH RETENTION RATES ON CALCULUS I}

Abstract

The retention rates on Calculus $I$ is an issue of the higher education, being above the mean of other courses and damaging STEM (Science, Technology, Engineering e Mathematics) professionals' development. Thus, the Calculus Marathon Project was established aiming to stimulate students to study this subject through a mathematics competition in which students challenge each other to solve derivative of first order functions. This article presents qualitative and quantitative analysis of the project development between 2016 and 2019 at Federal University of Santa Catarina, Technological Campus of Joinville. For, it was analyzed the subscription form of the event, then it was made a survey with students engaged on calculus courses and it was done interviews with participants of the competition. Finally, the Project has proved to be effective to benefit the student's logical development and promote soft-skills, as well as promoting a healthier university campus.

Keywords: Differential and Integral Calculus; Mathematics Games; Calculus Marathon.

\section{ESTUDIO DEL MARATÓN DE CÁLCULO COMO INTERVENCIÓN PARA LOS ALTOS NIVELES DE REPROBADOS EN CÁLCULO I}

\section{Resumen}

El nivel de alumnos reprobados en Cálculo Diferencial e Integral es un problema para la educación superior que sobresale frente a otras disciplinas de pregrado y perjudica la formación de profesionales en las Ciencias Exactas. Debido a esto, para mejorar e incentivar el estudio, se creó el proyecto llamado Maratón de Cálculo, el cual es una competencia de matemáticas en la que los estudiantes se desafían a sí para la resolución de derivadas de funciones de una variable. Este artículo presenta un análisis cualitativo y cuantitativo de la ejecución de este proyecto desarrollado entre 2016 y 2019 en la Universidad Federal de Santa Catarina, Centro Tecnológico Joinville. Para ello, los análisis fueron realizados mediante un formulario de inscripción del evento, un cuestionario online para los matriculados en disciplinas relacionadas con Cálculo y entrevistas a los participantes. Finalmente, el proyecto demostró ser efectivo para el desarrollo de la lógica y las habilidades de los estudiantes, además de contribuir con la creación de una universidad más agradable.

Palavras clave: Cálculo Diferencial e Integral; Juegos Matemáticos; Maratón de Cálculo. 
Estudo da maratona de cálculo como intervenção para o elevado índice de retenção em Cálculo I

\section{INTRODUÇÃO}

Os níveis de retenção em Cálculo Diferencial e Integral I (CDI I) são um problema da realidade do ensino superior brasileiro como um todo e se estende, também, para o ponto de vista internacional (PEREIRA, 2009). Sendo esta uma disciplina elementar do ciclo básico dos cursos de Engenharia e demais ramos das Ciências Exatas, evidencia-se o problema de os alunos não terem aproveitamento positivo com a mesma.

Nos anexos de sua tese de doutorado, Barufi (1999) mostra que as porcentagens de nãoaprovados em CDI I na Universidade de São Paulo (USP), entre os anos de 1990 e 1995, variaram entre 13\% e 79\% na Escola Politécnica. Já no Instituto de Geociências, este índice chegou a 83\% em 1990. Embora algumas turmas tivessem obtido resultados positivos na disciplina de CDI I, nota-se que estas fazem parte de uma minoria e que, no âmbito da universidade, os discentes em geral não estavam preparados para concluir a disciplina.

Santos et al (2001), por sua vez, ao comparar o desempenho de estudantes em diferentes disciplinas, revela que, dentre os sete cursos de engenharia da Universidade Federal de Ouro Preto, “[..] os mais baixos índices de aprovações foram identificados em Cálculo I do $1^{\circ}$ período” (Santos et al, 2001, p. 7). Segundo o autor, a porcentagem máxima de aprovados em Cálculo I foi de 54\%, na turma de Engenharia de Produção, chegando a apenas 36\%, na turma de Engenharia Geológica. Com essa afirmação, pode-se perceber que, apesar das dificuldades encontradas pelos estudantes nas demais disciplinas do ciclo básico de seus cursos, CDI I é um caso especial, uma vez que estas dificuldades não são exclusivas de um pequeno grupo de estudantes, mas compartilhadas pela maioria.

Ainda nesse viés, no primeiro capítulo de sua dissertação, Pereira (2009) revela que a taxa de não-aprovação nos cursos de Cálculo I na Universidade Federal do Rio de Janeiro (UFRJ), no $2^{\circ}$ semestre de 2005, foi de 47\%. Similarmente, Pontes et al (2012), em um estudo de caso com estudantes de Engenharia de Alimentos da Universidade Federal do Pará (UFPA), constatou que, entre 2009 e 2011, a taxa de retenção variou entre 62\% e 78\%.

Esses dados alarmantes (Barufi, 1999; Santos et al, 2001; Pereira, 2009; Pontes et al, 2012), distribuídos geograficamente e ao longo do tempo por todo o Brasil, demonstram a fragilidade no ensino de uma matéria importante para a formação de profissionais de diversas áreas.

Agrava-se ainda esse contexto: Rafael (2017) evidenciou, através do gráfico apresentado na Figura 1, que a maior parte dos estudantes necessita de mais de um semestre para serem aprovados em CDI I e que, dentre os repetentes, a maioria continua retida após cursar a disciplina pela segunda vez. Embora sejam casos atípicos, é preocupante que existam alunos cujo tempo necessário para a 
aprovação em CDI I chegue a onze semestres, ou seja, número superior ao tempo de formatura de um aluno regular.

Figura 1 - Tempo necessário para a aprovação em cálculo

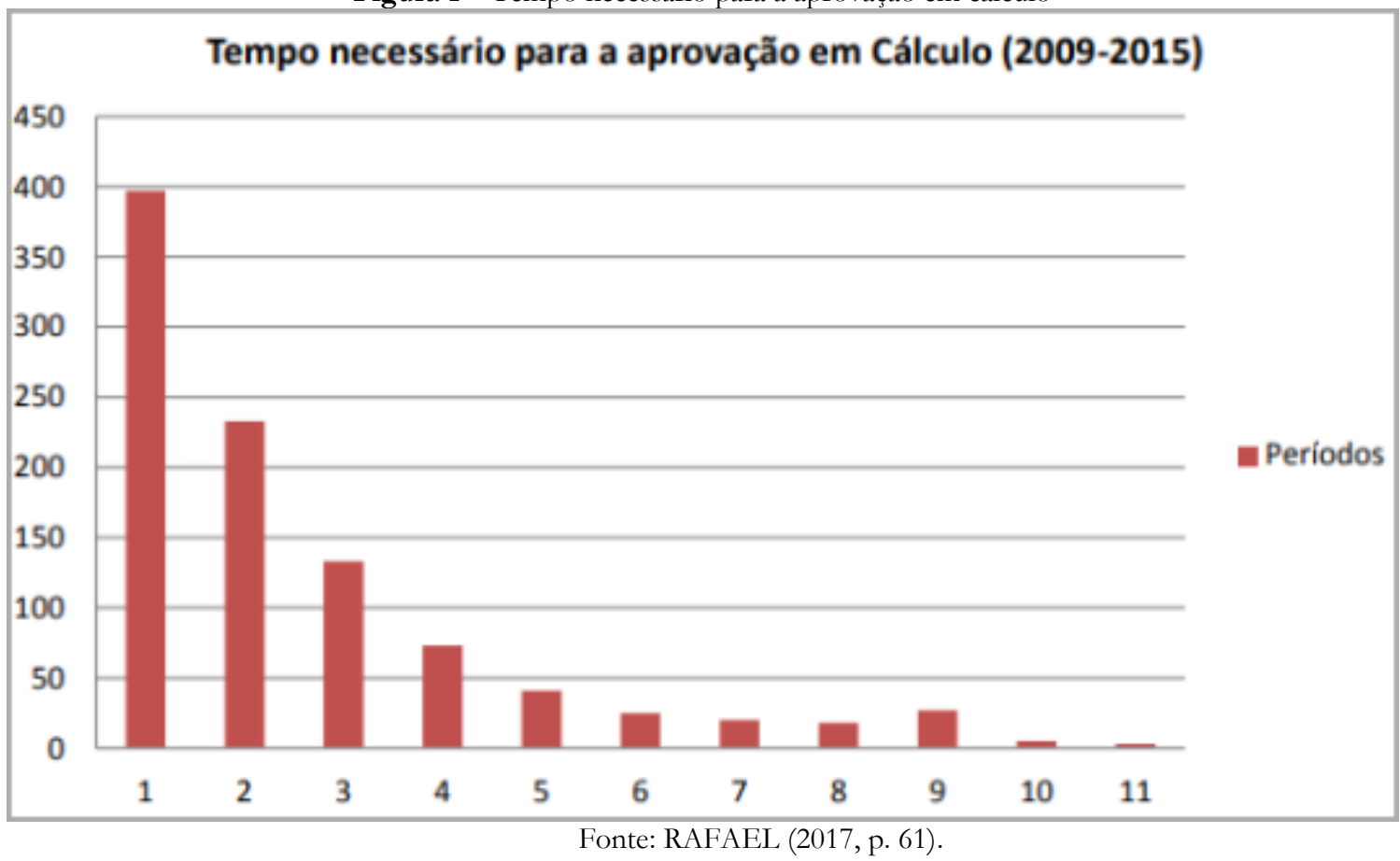

Conclusão igualmente importante foi realizada por Pontes et al, que estudou o desempenho de alunos aprovados e retidos em CDI I ao longo do curso de Engenharia de Alimentos. Para tanto, ele observou os índices de aprovação, retenção e de alunos que ainda não haviam cursado disciplinas que utilizam conceitos trabalhados em CDI I desses dois grupos de alunos (aprovados e retidos). Ao fim do trabalho, ele constatou que

[.... o que se observa nos cursos de engenharia em geral é que uma parcela significativa dos alunos não consegue apresentar um desempenho bom na disciplina Cálculo I e estas deficiências se projetam ao longo do curso impedindo que o aluno obtenha êxito em disciplinas posteriores que exijam as habilidades do cálculo diferencial e integral.

(Pontes et al, 2012, p. 1)

Assim, o autor conclui que estudantes retidos em CDI I tendem a reprovar em outras matérias do conhecimento que envolvam conceitos aprendidos nessa disciplina.

Essa dificuldade acadêmica - queda no desempenho acadêmico e consequente desmotivação - é interpretado como uma das principais causas da evasão da universidade (RAFAEL, 2017, p. 26).

No caso em que há evasão, assume-se que houve dano tanto ao aluno, que deixou de concluir o curso no qual se matriculou, quanto à universidade, que sofre uma perda social e financeira. 
Estudo da maratona de cálculo como intervenção para o elevado índice de retenção em Cálculo I

Nesse contexto, a realidade da Universidade Federal de Santa Catarina - Centro Tecnológico de Joinville (UFSC - CTJ) não difere das demais universidades brasileiras no que se refere às deficiências do ensino e aprendizado de CDI I. Atualmente, a universidade oferece 8 cursos de graduação, sendo eles: Bacharelado em Ciência e Tecnologia, Engenharia Aeroespacial, Engenharia Automotiva, Engenharia Civil de Infraestrutura, Engenharia de Transportes e Logística, Engenharia Ferroviária e Metroviária, Engenharia Mecatrônica e Engenharia Naval. Todos os cursos apresentam CDI I como disciplina da primeira fase.

Ao estudar dados coletados junto à secretaria da UFSC - CTJ, percebeu-se que a taxa de aprovação da matéria por semestre, desde o início de 2012 até o fim de 2019, variou entre 20\% (2014.2) e 38\% (2019.1) de aprovações por semestre, como mostra o Quadro 1. Assim, o número de repetentes foi maior que o número de aprovados na matéria em todo o período analisado.

Quadro 1 - Taxa de Aprovação em CDI I por Semestre

\begin{tabular}{|l|l|l|l|}
\hline Semestre & Taxa de Aprovação $(\%)$ & Taxa de Retenção $(\%)$ & Taxa de FI $(\%)$ \\
\hline 2012.1 & 22.03 & 77.97 & 17.81 \\
\hline 2012.2 & 27.78 & 72.22 & 19.65 \\
\hline 2013.1 & 28.57 & 71.43 & 7.67 \\
\hline 2013.2 & 21.05 & 78.95 & 18.11 \\
\hline 2014.1 & 38.77 & 61.23 & 14.41 \\
\hline 2014.2 & 20.5 & 79.5 & 19.88 \\
\hline 2015.1 & 29.52 & 70.48 & 18.14 \\
\hline 2015.2 & 25.69 & 74.31 & 21.4 \\
\hline 2016.1 & 34.73 & 65.27 & 17.08 \\
\hline 2016.2 & 29.01 & 70.99 & 11.18 \\
\hline 2017.1 & 35.84 & 64.16 & 17.36 \\
\hline 2017.2 & 31.72 & 68.28 & 17.67 \\
\hline 2018.1 & 30.46 & 69.54 & 19.6 \\
\hline 2018.2 & 26.18 & 73.82 & 20.9 \\
\hline 2019.1 & 38.97 & 61.03 & 13.39 \\
\hline 2019.2 & 29.04 & 70.96 & 16.84 \\
\hline
\end{tabular}

Fonte: Secretaria da UFSC - CTJ.

Outro dado importante do Quadro 1 é o número elevado de discentes que reprovaram em CDI I por Frequência Insuficiente (FI), isto é, quando o aluno possui $25 \%$ ou mais de faltas em relação ao número total de Horas Aula da matéria. Também é possível perceber que em 12 dos 16 semestres analisados esta taxa ultrapassou $15 \%$.

Com o fim de ajudar os discentes a alcançarem melhores resultados no aprendizado do cálculo, foi inserido na UFSC - CTJ o evento Maratona de Cálculo: uma competição de conhecimentos relacionados a conceitos matemáticos aprendidos na disciplina de CDI I. 
Estudo da maratona de cálculo como intervenção para o elevado índice de retenção em Cálculo I

Este artigo tem por objetivo analisar o impacto deste projeto como medida interventiva para os elevados índices de reprovação em disciplinas do ciclo básico de engenharia e, consequentemente, a evasão dos graduandos. Ademais, pretende-se compreender a contribuição para o desenvolvimento dos estudantes da UFSC - CTJ.

Primeiramente será apresentado o projeto Maratona de Cálculo, bem como sua fundamentação, na seção "Causas da retenção e medidas interventivas". Em seguida a seção "Materiais e Métodos" trará informações sobre como buscou-se compreender o impacto do projeto na comunidade discente e a seção "Resultados e Análises" apresentará os resultados dessa investigação. Por fim, a seção "Considerações finais" abordará as principais conclusões deste trabalho.

\section{CAUSAS DA RETENÇÃO E MEDIDA INTERVENTIVA}

Ao comparar livros usados no ensino de cálculo, Barufi (1999) apresenta a contextualização da história da matemática e de resolução de problemas como passo fundamental para o processo de ensino-aprendizagem. A autora parte do princípio de que a matemática não deve ser ensinada de forma mecânica, usando somente a exposição de conhecimentos do professor ao aluno, mas também, partir do ponto que este deve ser capaz de desenvolver-se por si só e o professor deve ser um intermediador, que o instigue a entender o assunto proposto por meio de perguntas e exemplos que aproximem o cálculo da realidade individual do estudante.

Este ponto de vista, que estende o ensino para além da transmissão contínua de informações e repetição de exercícios, permite a possibilidade do ensino de CDI I utilizando-se de jogos como instrumento didático. Nesse viés, Grado (2004) apud Mota (2009) discorre sobre as vantagens do uso de jogos como ferramenta de ensino, das quais ressaltam-se oito pontos positivos que poderiam adequar-se à realidade da UFSC - CTJ:

Quadro 2 - Vantagens do uso de jogos como ferramenta de ensino

1. Desenvolvimento de estratégias de resolução de problemas (desafio dos jogos);

2. Aprender a tomar decisões e saber avaliá-las;

3. O jogo requer a participação ativa do aluno na construção do seu próprio conhecimento;

4. O jogo favorece a integração social entre os alunos e a consciencialização do trabalho em grupo;

5. A utilização dos jogos é um fator de interesse para os alunos; 
6. Dentre outras coisas, o jogo favorece o desenvolvimento da criatividade, do senso crítico, da participação, da competição "sadia", da observação, das várias formas de uso da linguagem e do resgate do prazer em aprender;

7. As atividades com jogos podem ser utilizadas para desenvolver habilidades de que os alunos necessitam;

8. As atividades com jogos permitem ao professor identificar e diagnosticar algumas dificuldades dos alunos.

Fonte: GRANDO, 2004, p. 31 - 32 apud MOTA, 2009, p. 38.

Diante disso, com objetivo de melhorar o desempenho dos estudantes da UFSC - CTJ na disciplina de CDI I, foi estabelecido no campus o evento Maratona de Cálculo.

O evento é uma competição na qual duplas se desafiam na resolução de problemas relacionados ao cálculo, tendo por objetivo resolvê-los o mais rápido possível. Em um primeiro momento, as duplas passam por uma fase classificatória em que cada intervalo de tempo gasto na solução do problema equivale a uma dada pontuação. Após isso, são selecionadas as duplas que mais pontuam e, em seguida, elas competem em fase eliminatória de mata-mata (oitavas de final, quartas de final, semifinal e final).

Em relação à temática do evento, CDI I abrange muitos assuntos e nem todos os problemas propostos pela disciplina podem ser resolvidos rapidamente através de leis previamente estabelecidas e sem necessidade de um olhar analítico profundo. Portanto, dados os três conceitos matemáticos bases da disciplina (o limite, a derivada e a integral), escolheu-se a derivada de funções de uma variável como sendo o desafio a ser resolvido, por ser a operação que mais se enquadraria com o perfil proposto pelo evento. Ainda, este tripé matemático (limite, derivada e integral) é valoroso para a elaboração de problemas mais complexos dentro das Exatas e acompanha os estudantes durante toda a sua trajetória na universidade, sendo resgatado no desenvolvimento de equações e teorias aplicadas à Engenharia.

A competição é aberta para todos os discentes da UFSC - CTJ, sendo que aqueles que cursam CDI I e CDI II são particularmente incentivados a participarem do evento. Essa metodologia de ensino é uma adaptação do evento Rei da Derivada (disponível em: http://www.reidaderivada.com), desenvolvido inicialmente na Universidade de Brasília (UnB).

O projeto Maratona de Cálculo é ainda uma ação extensionista, por organizar também o Torneio Interinstitucional de Derivadas, competição semelhante realizada em parceria com outras universidades da região Sul brasileira, como Universidade Tecnológica Federal do Paraná (UTFPR), Pontifícia Universidade Católica de Curitiba (PUC), Católica de Santa Catarina e Universidade do 
Estudo da maratona de cálculo como intervenção para o elevado índice de retenção em Cálculo I

Vale do Itajaí (UNIVALI). No torneio, finalistas de maratonas internas de cada instituição se enfrentam na resolução dos exercícios propostos, promovendo assim o espaço propício para a troca de ideias a respeito de ensino e aprendizagem da disciplina de CDI I.

\section{MATERIAIS E MÉTODOS}

Para o desenvolvimento desta pesquisa, adotou-se a análise quali-quantitativa. Primeiramente, foram reunidas informações provenientes do formulário de inscrições da Maratona de Cálculo. Assim, foram obtidos os números de matrículas dos participantes do evento nos anos de 2017, 2018 e 2019, bem como os cursos e semestres de ingresso de cada inscrito. Com isso, foi possível reconhecer o perfil dos participantes e verificar quais populações aderiram ao evento de forma mais significativa. Ainda nesse viés, foi analisado o desempenho dos estudantes na primeira fase da competição, utilizando como espaço amostral os anos de 2018 e 2019.

Em seguida, com o objetivo de identificar o impacto da maratona dentre a comunidade da UFSC - CTJ, criou-se um formulário online, através da ferramenta Google Forms, com perguntas intencionadas a avaliar a percepção dos estudantes acerca do evento e de sua experiência pessoal com o projeto. Para tanto, foram feitas perguntas diferenciadas para aqueles que participaram da maratona e para aqueles que não. Após isso, visitou-se todas as turmas de CDI I, CDI II e Cálculo Vetorial da universidade no primeiro semestre de 2019 (2019.01) e foi solicitado aos estudantes que acessassem o formulário online. Nesta etapa foram coletadas 208 respostas.

Por fim, realizou-se entrevistas com maratonistas com o objetivo de identificar as motivações que os estudantes tiveram para participarem do evento e buscou-se entender se o evento exerceu seu objetivo ao contribuir para o desenvolvimento dos discentes. Assim, cinco duplas foram entrevistadas e gravadas entre os dias 17 de abril de 2020 e 30 de abril de 2020. Das duplas, duas foram selecionadas por serem as finalistas da edição 2019 do evento e as demais três foram sorteadas a partir da ficha de inscrição por meio de uma plataforma online. Ainda, devido às circunstâncias de isolamento social referentes à pandemia da Covid-19, todas as entrevistas foram realizadas remotamente por meio dos softwares Hangouts, Whats App Web e Conferência Web, segundo a disponibilidade dos entrevistados. Para manter a identidade dos discentes em sigilo, cada participante será identificado apenas pelas suas iniciais e pelo tipo de participação que teve no evento. 
Estudo da maratona de cálculo como intervenção para o elevado índice de retenção em Cálculo I

\section{RESULTADOS E ANÁLISES}

Primeiramente, buscou-se verificar se o evento estava atingindo o público-alvo inicial, ou seja, estudantes que estão no ciclo básico e, portanto, cursando CDI I ou disciplinas relacionadas. Assim, foi analisado qual o semestre de ingresso dos inscritos. Também, foi verificado o curso dos maratonistas para entender se existia homogeneidade na adesão dos alunos.

O gráfico apresentado na Figura 2 considerou quantos semestres letivos o estudante havia cursado desde o seu ingresso na universidade, contando com o da realização da maratona.

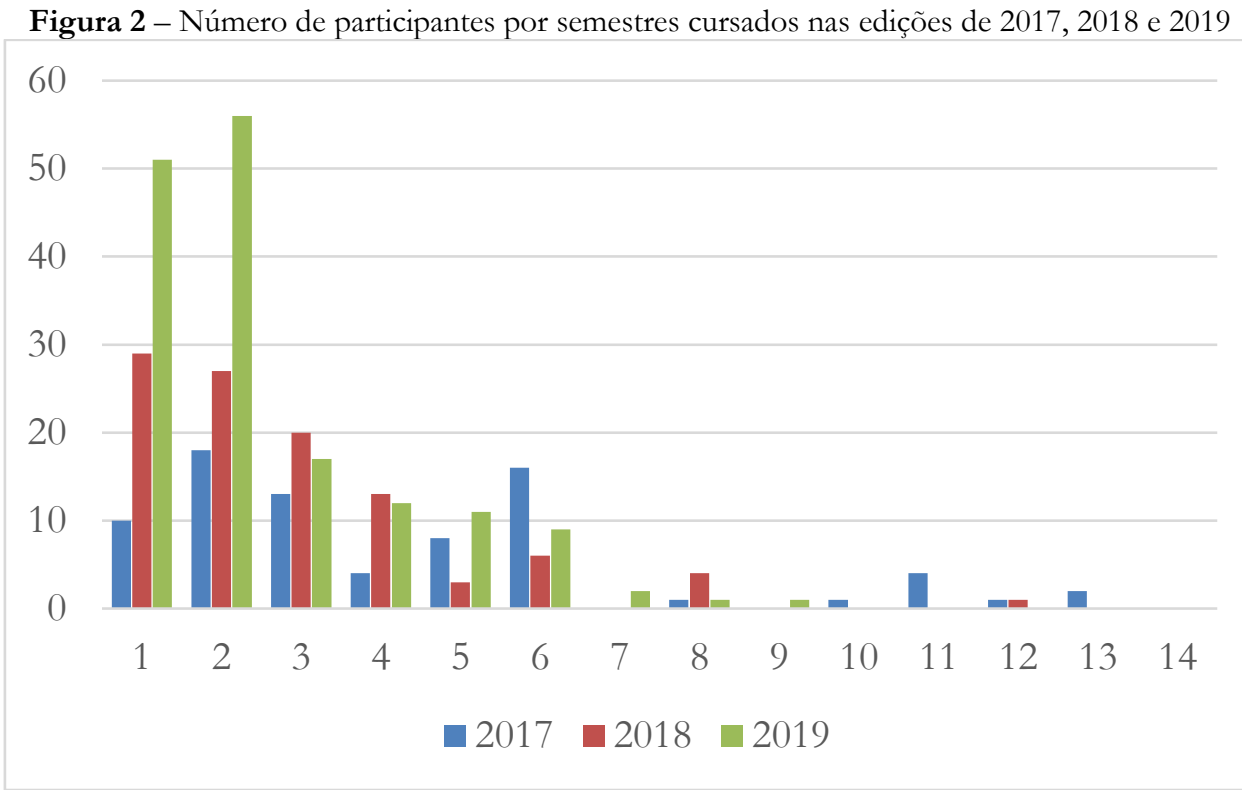

Fonte: elaborado pelos autores.

No ano de 2017, constata-se que havia participantes com mais de 12 semestres cursados. Apesar disso, 52\% dos maratonistas haviam cursado três semestres ou menos. Ou seja, eram alunos das fases iniciais.

No ano seguinte, $70 \%$ dos participantes do evento eram alunos ingressos na universidade há três períodos ou menos. Já em 2019, esse número foi de 77\%. Desta forma, pode-se observar que em todos os anos estudados o público-alvo foi alcançado.

Acerca dos cursos dos graduandos, constata-se que dentre os 78 participantes de 2017 e os 103 de 2018, a maior parte dos inscritos em ambos os anos eram dos cursos de Engenharia Mecatrônica e de Engenharia Aeroespacial. Nos dois anos, o percentual de maratonistas destes dois cursos somou 63\% do total inscrito. Todavia, em 2019, discentes dos cursos de Engenharia Civil de Infraestrutura, Engenharia Naval e Engenharia de Transporte e Logística se engajaram no evento de forma significativa, de forma que o evento alcançou a participação de 160 estudantes. Este aumento pode ser justificado pela maior divulgação da Maratona de Cálculo por meio da rede 
social Instagram, pelo envolvimento dos professores de CDI I destes cursos no projeto e pela caracterização particular destas turmas, que se mostraram mais propícias ao envolvimento em atividades extracurriculares.

Figura 3 - Número de participantes por curso

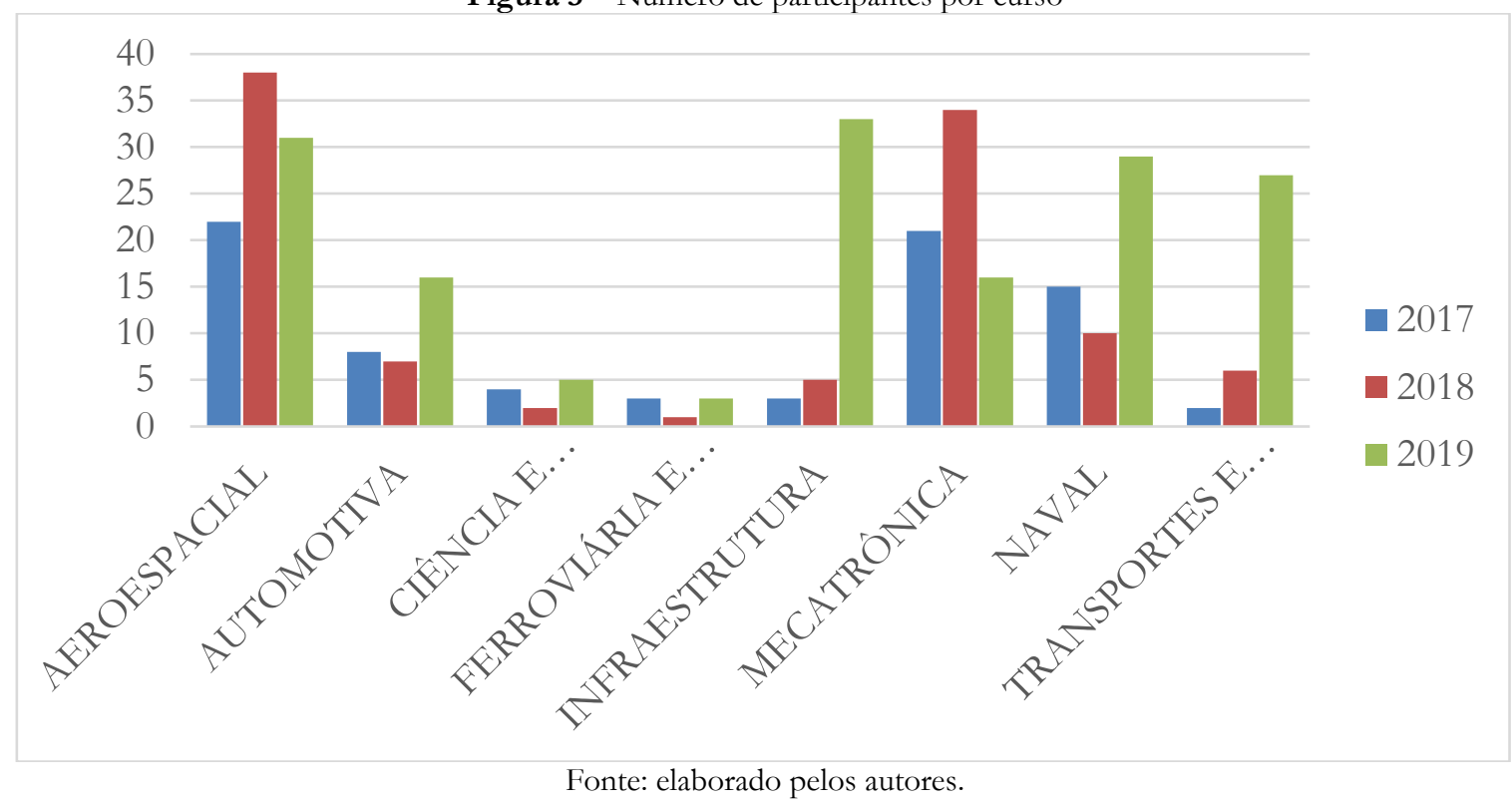

Em relação ao desempenho dos estudantes, fez-se uma breve análise acerca das pontuações obtidas na primeira fase de 2018 e de 2019. Nesta etapa, os alunos são desafiados a resolver derivadas de equações mais simples e que buscam classificá-los pela velocidade. O objetivo é avaliar o foco, a memória, o trabalho em dupla e a prontidão em resolver problemas.

Foram aplicadas 10 questões com pontuação variando entre 0 e 10 para respostas corretas, de acordo com o tempo de entrega. A pontuação média em 2018 foi de 32,79 pontos, com desvio padrão igual a 21,72. Assim, os alunos classificados para a segunda fase tiveram pontuação entre 42 e 76 pontos. O histograma gerado pode ser visto a seguir. 
Estudo da maratona de cálculo como intervenção para o elevado índice de retenção em Cálculo I

Figura 4 - Histograma da Pontuação da primeira fase de 2018

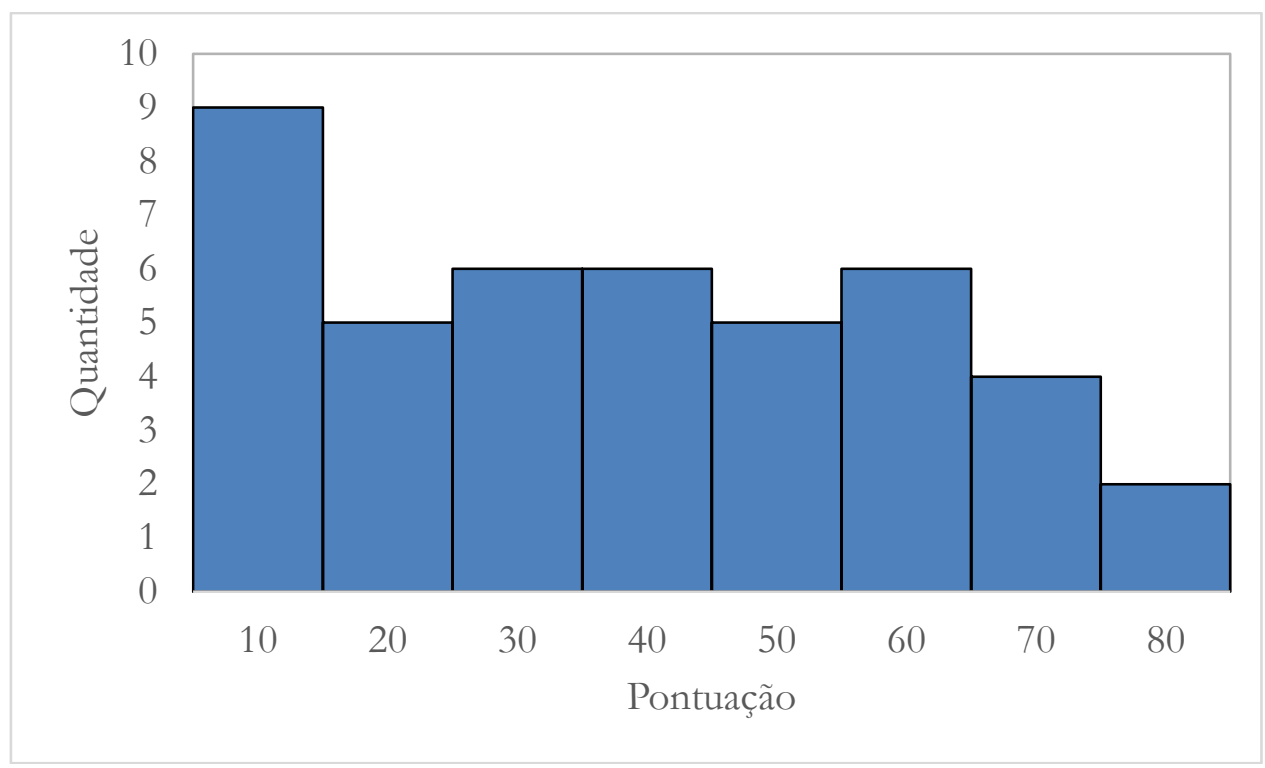

Fonte: elaborado pelos autores.

Em 2019, a pontuação média dos estudantes foi de 23,01 pontos e o desvio padrão foi de 19,13. Os classificados para a segunda etapa obtiveram entre 32 e 86 pontos.

Figura 5 - Histograma da Pontuação da primeira fase de 2019

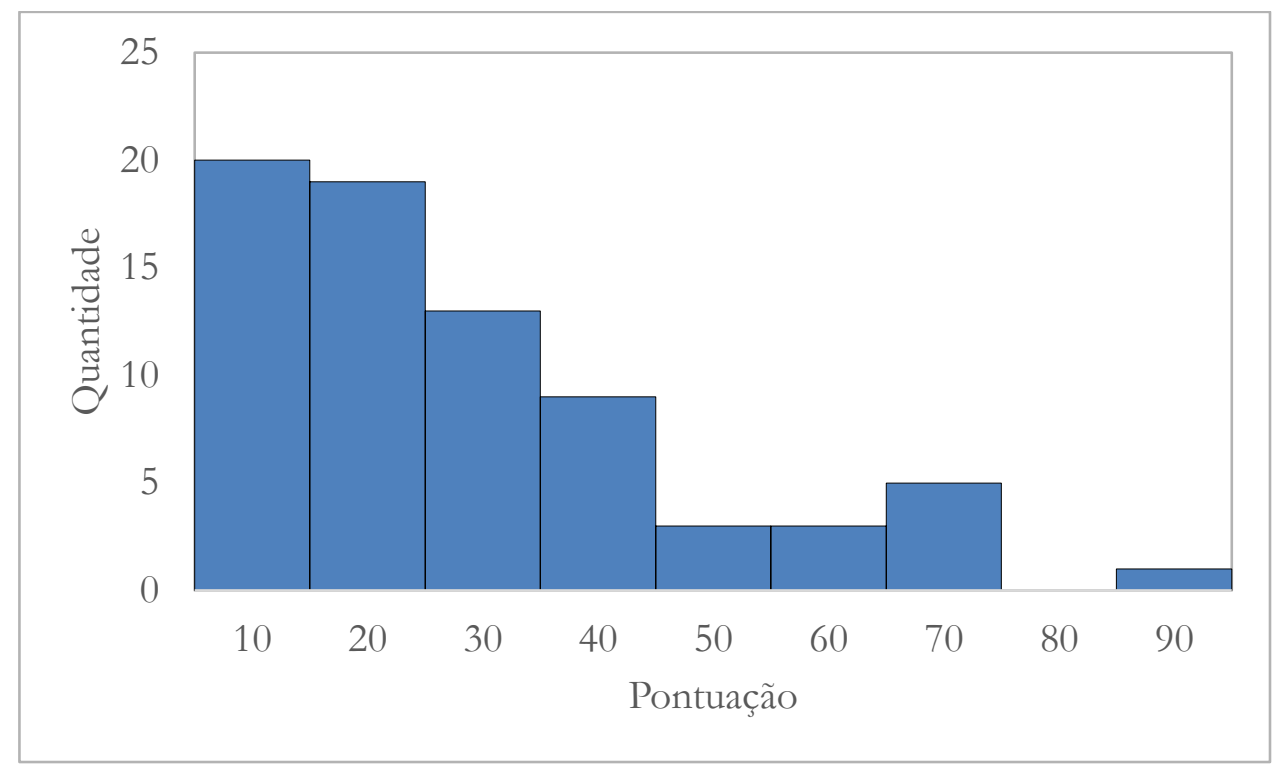

Fonte: elaborado pelos autores.

É possível observar que a maior parte dos competidores não alcança a metade da pontuação total. Este dado retrata a dificuldade que os estudantes possuem com a temática e o despreparo para lidar com o nervosismo e a pressão que o evento proporciona. 
Já a segunda fase envolve apenas os participantes que tiveram as melhores pontuações na fase anterior. Nesta etapa, os problemas são mais complexos e busca-se avaliar a familiaridade dos estudantes com diversas regras de derivação e sua aplicação de maneira rápida e eficiente na resolução das derivadas apresentadas. Alguns exemplos das questões utilizadas em ambas as fases da competição podem ser observados no Quadro 3.

\begin{tabular}{|c|c|}
\hline \multicolumn{2}{|c|}{ Quadro 3- Questões exemplo } \\
\hline$y=\frac{10}{\sqrt[5]{x}}+\sqrt[3]{x}$ & Primeira fase \\
\hline$y=\cos \left(x \cdot e^{x^{2}+1}\right)$ & Primeira fase \\
\hline$y=\ln \left(\ln \left(\operatorname{sen}\left(e^{x^{2}+1}\right)\right)\right)$ & Segunda fase \\
\hline$y \cdot e^{x^{2}+y^{2}}=\ln \left(x^{2}\right) \cdot \sec (2 x)$ & Segunda fase \\
\hline
\end{tabular}

Fonte: elaborado pelos autores.

No formulário aplicado em sala de aula, foi perguntado se o aluno havia participado da Maratona de Cálculo em alguma edição. Dos respondentes, 28 marcaram "sim” e 180 marcaram "não".

Àqueles que participaram da competição, foi perguntado o motivo de o terem feito. Cada aluno poderia selecionar mais de uma resposta. A priori, foram sugeridas três respostas (Integração com demais participantes, pontuação extra em cálculo e premiação), contudo os alunos ainda adicionaram outras opções. Das respostas, 71,4\% correspondem a "Pontuação extra em cálculo", haja vista que alguns professores optaram por bonificar os alunos participantes. Este dado mostra ainda a necessidade dos estudantes em aumentar a média da matéria, de forma que alguns décimos podem ser decisivos na aprovação ou não na disciplina.

Importante salientar que dois estudantes revelaram participar do evento por se identificarem com o assunto abordado, mostrando que também existe interesse por parte dos alunos em desenvolver o cálculo como um conteúdo amigável, algo que não havia sido previsto nas respostas sugeridas do formulário. 
Figura 6 - Motivação para participar do evento

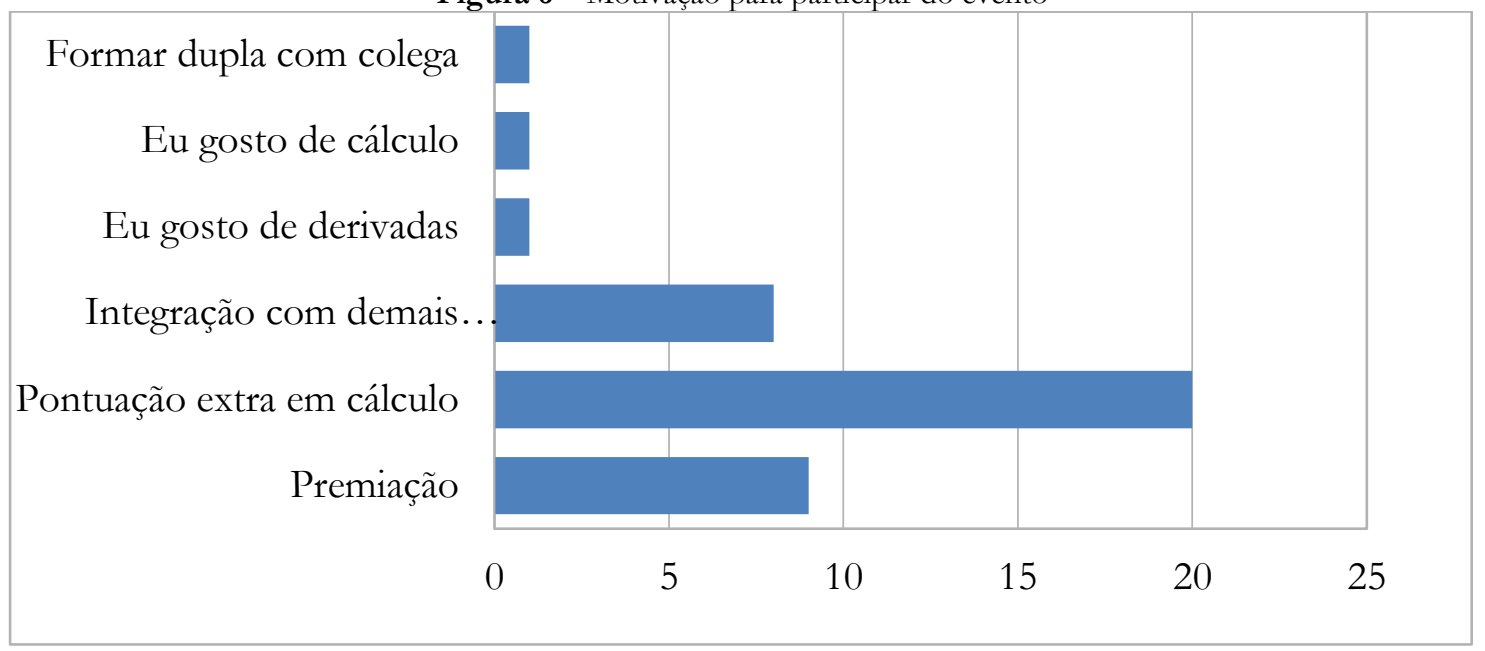

Fonte: elaborado pelos autores.

De forma análoga, os alunos que não participaram da Maratona de Cálculo foram questionados sobre o motivo. Destaca-se falta de confiança para resolver os exercícios propostos $(63,9 \%)$, seguido por vergonha de resolver derivadas em público $(35,6 \%)$ e medo de errar os exercícios $(33,9 \%)$.

Figura 7 - Motivos de não participar da maratona

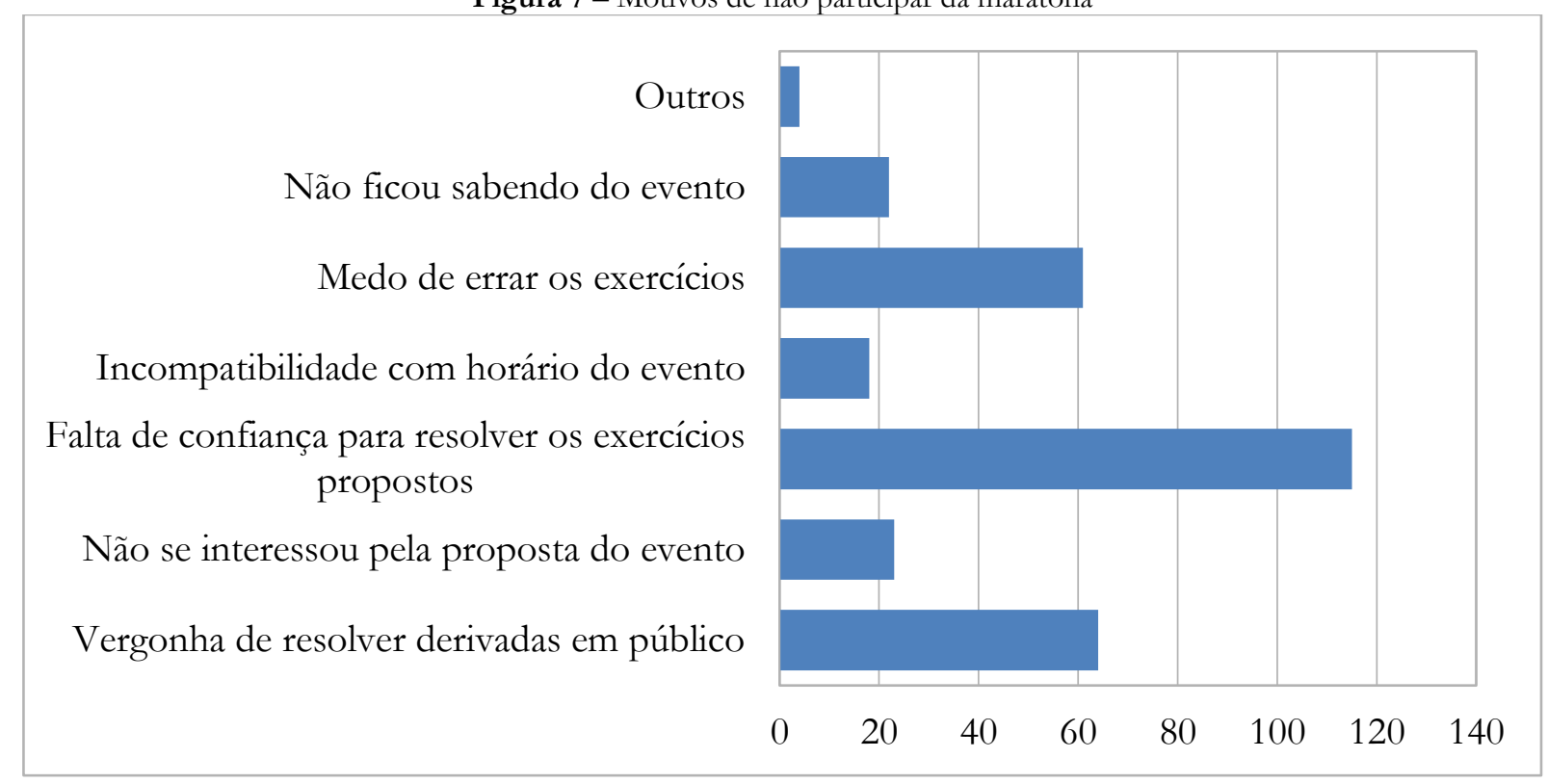

Fonte: elaborado pelos autores.

Uma segunda análise realizada, foi acerca dos índices de aprovação e retenção em CDI I e CDI II, comparando maratonistas e não-maratonistas no segundo semestre de 2018 (2018.02). Para tanto, o formulário aplicado em sala de aula perguntava qual matéria o aluno havia cursado no semestre 2018.02 e qual matéria estava cursando em 2019.01. Desta forma, foi considerado retido o aluno que respondeu estar cursando a mesma disciplina nos dois semestres; "Aprovado em 
Estudo da maratona de cálculo como intervenção para o elevado índice de retenção em Cálculo I

Cálculo I” o discente que afirmou ter cursado Cálculo I em 2018.2 e Cálculo II em 2019.1; e “Aprovado em Cálculo II” quando afirmou ter cursado Cálculo II em 2018.2 e Cálculo Vetorial em 2019.1. Foram desconsiderados para esta análise os casos em que esta inferência não podia ser feita de forma direta.

Figura 8 - Índices de aprovação de não participantes da maratona

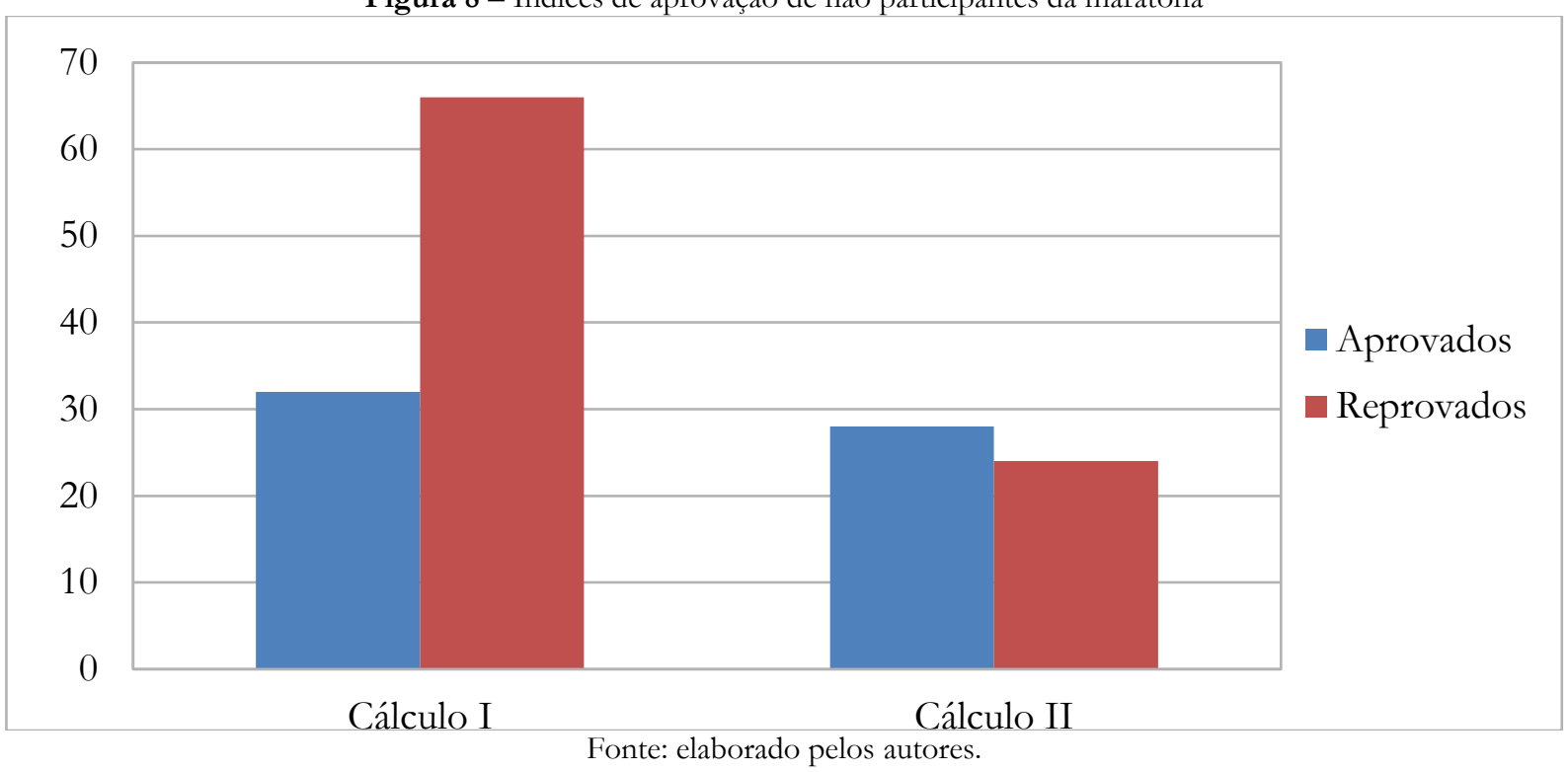

Os dados obtidos mostram que dentre os não-maratonistas, o índice de não-aprovação em CDI I e CDI II foram respectivamente de $67 \%$ e $46 \%$. Dado que espelha a realidade da UFSC CTJ, como apresentado no Quadro 1, onde mostrou-se que os índices de retenção em CDI I variaram entre $79 \%$ e 61\% durante o período de 2012 a 2019.

Por sua vez, o índice de retenção foi de apenas 23\% em CDI I para os maratonistas, sendo que não foram constatadas reprovações em CDI II dentre eles. 
Figura 9 - Índices de aprovação de participantes da maratona

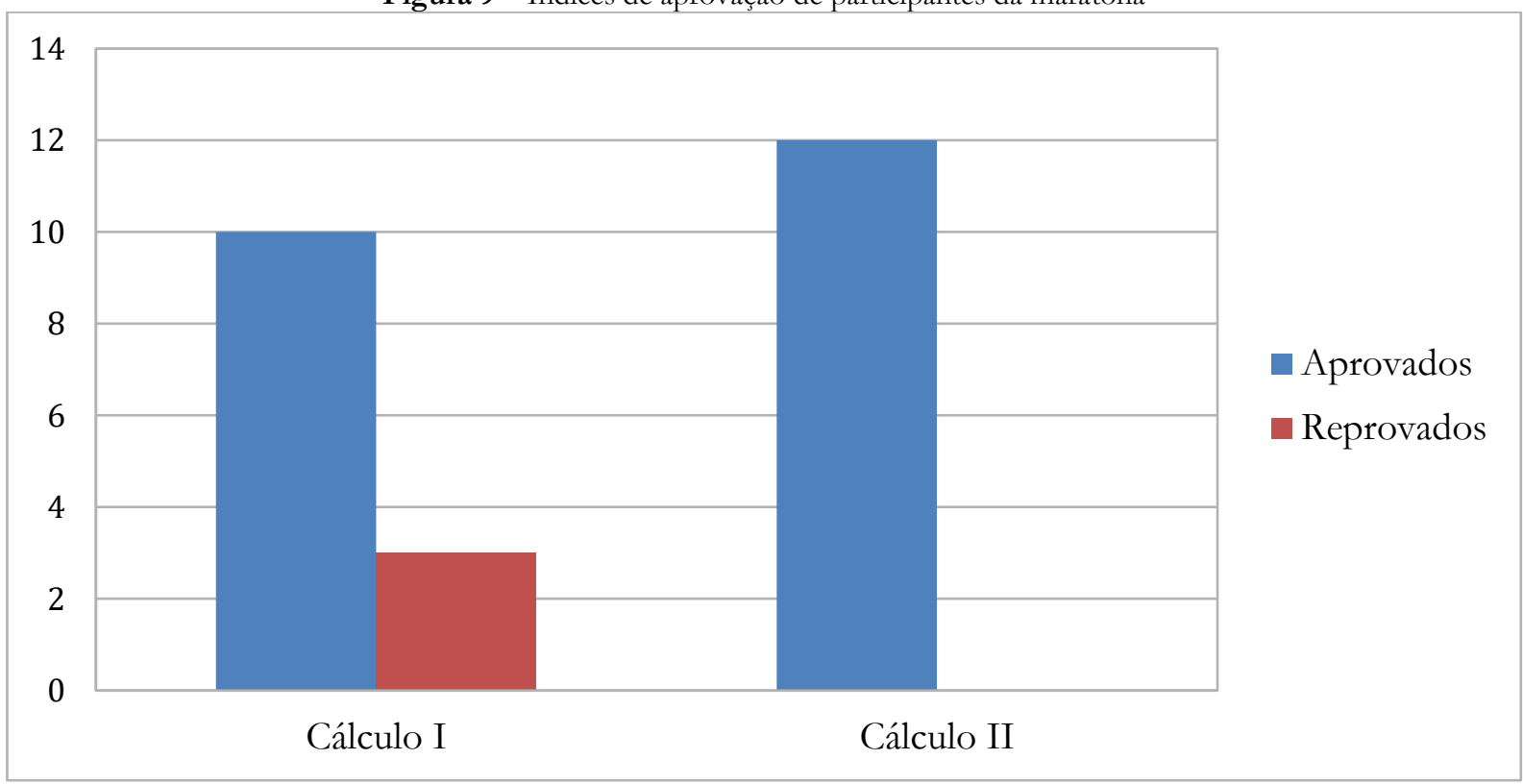

Fonte: elaborado pelos autores.

Assim, evidencia-se que dentre os maratonistas houve um percentual de aprovação nestas disciplinas superior ao dos demais discentes do campus, o que provoca o questionamento de se isso acontece devido à medida interventiva ou se o perfil dos participantes do evento é de alunos que não tinham grandes dificuldades com a disciplina e, portanto, possuíam maiores chances de concluí-la com sucesso.

Ainda nesta linha, a Tabela 1, construída através dos dados do Quadro 1, retrata uma diminuição na média das taxas de retenção em 3,97\% após o início da realização do evento, bem como uma redução no desvio padrão dos valores respectivos a cada período. Apesar destes resultados representarem uma suave melhora nas perspectivas do campus, não é um dado consistente que pode levar a conclusões científicas.

Tabela 1 - Taxas de retenção na UFSC - CTJ antes e após o início do evento no campus

\begin{tabular}{lll}
\hline Semestres & Média Retenção (\%) & DDP (\%) \\
2012.1 a 2016.1 & 72.37 & 6.21 \\
2016.2 a 2019.2 & 68.40 & 4.40 \\
\hline
\end{tabular}

Por fim, os participantes da pesquisa foram questionados sobre "quanto a maratona contribuiu para seus estudos". O gráfico da Figura 10 mostra que 48,15\% dos respondentes consideram que a maratona contribuiu para seus estudos em nível bom ou excelente, 47,83\% acreditam que houve contribuição intermediária e 13,04\% consideram que a maratona contribuiu pouco ou nada. 
Figura 10 - Contribuição da maratona durante os estudos

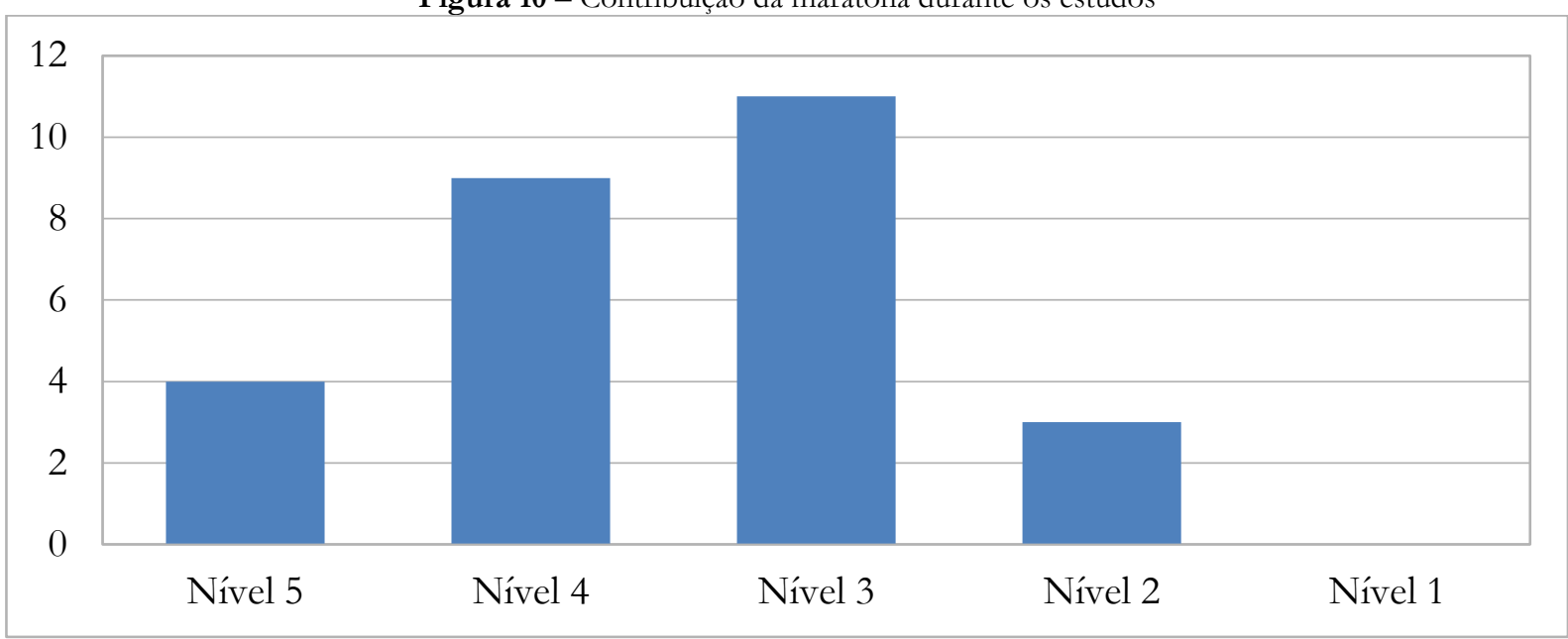

Fonte: elaborado pelos autores.

Neste sentido, percebe-se que, embora não se possa concluir uma relação direta entre o número de aprovados em CDI I e o estabelecimento do evento, os alunos ainda consideram ter sido ajudados com o projeto. Isso ocorre devido ao caráter lúdico da maratona, que permite o desenvolvimento de outras habilidades nos estudantes, também importantes para a vida acadêmica. Como sugere o Quadro 2, as vantagens dos jogos se estendem para além do ensino do próprio conceito envolvido e abrange o entretenimento e o desenvolvimento holístico do estudante.

Nesta linha, todas as duplas entrevistadas relataram que a participação no evento tem contribuído no desenvolvimento do raciocínio lógico dos estudantes, como discorreu uma das integrantes da dupla campeã:

"A maratona vai ajudar realmente a você ter um raciocínio mais rápido. Como que en vou sair dessa situação, desse problema com pressão, com as pessoas te vendo e com o tempo. Então acho que não só para o cálculo haverá contribuição, mas para todas as outras matérias e situações da vida, trabalho, essas coisas." (V, campeã)

Além disso, outros estudantes relataram acreditar que a habilidade de derivação trouxe uma percepção nova sobre os problemas vistos durante a graduação (A, finalista) e que a participação no evento, concomitante à resolução mais rápida e precisa de derivadas, possibilitou que em disciplinas aplicadas à engenharia fosse possível prever se o resultado de uma conta a ser resolvida era promissor no início da resolução (W, finalista).

Ademais, os entrevistados ressaltaram a importância do evento na construção de soft skills, como apresentação em público e trabalho em grupo.

"Eu sou uma pessoa muito tímida, assim como muitas pessoas. Então eu me obriguei a ficar numa zona totalmente fora da zona de conforto. Estar lá na frente de todo mundo, todo mundo te vendo e você tem que fazer aquilo que sabe fazer. Então ajudou bastante (depois a gente teve apresentação de trabalho de Algebra) a não ter tanto medo, tanta 
Estudo da maratona de cálculo como intervenção para o elevado índice de retenção em Cálculo I

vergonha de tá lá na frente das pessoas, sabe? Isso ajudou bastante para mim.” (V, campeã)

Além disso, os alunos ainda discorreram sobre a importância de um evento envolvente e estimulante durante o semestre letivo de um curso de engenharia, que por muitas vezes carece de atividades recreativas no âmbito acadêmico. Neste tema, destaca-se dois pontos. O primeiro é acerca do alívio e descontração promovidos pela consolidação do evento: "Outro clima. Parece ser outra faculdade, em meio a época de prova, muito bom descontrair e relaxar um pouco" (I, maratonista), experiência que também é vivenciada por aqueles que participaram da segunda fase como plateia, na torcida pelas duplas finalistas, como apontado por alguns dos entrevistados. O segundo ponto é a integração com demais participantes, que também foi uma das motivações dos estudantes para participarem da maratona, como mostra a Figura 4.

"Eu acho que mais também pela experiência acadêmica, ver outras pessoas da universidade participando e interagindo, e sair de uma bolha. E como a gente era calouro, a gente vivia numa bolha, que a gente só conhecia os calouros e também a gente pode conhecer outras pessoas que já estavam em fases mais avançadas.” (A, maratonista)

\section{CONSIDERAÇÕES FINAIS}

Apesar da ausência de uma relação direta entre o número de aprovados em CDI I entre 2012 e 2019 e o estabelecimento do evento Maratona de Cálculo, pode-se perceber que ainda assim a maratona tem um impacto positivo na comunidade acadêmica, pois como foi mostrado na Figura 10, os alunos consideram que a maratona contribuiu de forma significativa em seus estudos. Esta perspectiva foi validada durante as entrevistas com duplas aleatórias de maratonistas, que discorreram sobre os benefícios de suas participações no evento no desenvolvimento de demais habilidades importantes para a vida acadêmica e para o mercado de trabalho, como: autoconfiança em apresentações em público, desenvolvimento de trabalho em grupo, melhora no raciocínio lógico e agilidade no desenvolvimento de contas.

Ademais, os discentes entrevistados revelaram a importância do caráter descontraído do evento, que possibilita momentos de lazer e consequente atenuação do estresse referente ao semestre letivo, bem como maior interação dos alunos das fases iniciais com seus veteranos e, portanto, engajamento acadêmico.

Dessarte, a Maratona de Cálculo pode ser compreendida como uma ferramenta para o envolvimento dos calouros e alunos iniciais na comunidade acadêmica, para além das fronteiras da sala de aula, uma vez que ela é uma das primeiras atividades extracurriculares que o discente tem 
Estudo da maratona de cálculo como intervenção para o elevado índice de retenção em Cálculo I

contato ao entrar na universidade. Assim, o evento assume caráter formador, ao construir a cultura de comprometimento do aluno com a universidade.

Desta forma, considera-se como positiva a implementação da Maratona de Cálculo na UFSC - CTJ, o que também pode ser verificado pelo número de participantes da competição que foi, respectivamente, de 78, 103 e 160 alunos em 2017, 2018 e 2019.

\section{AGRADECIMENTOS}

Agradecimentos à Isabel Silveira, que prontamente analisou a lista de inscritos do evento e nos forneceu os semestres de ingresso e curso de cada discente, para os fins usados neste artigo. $\grave{A}$ Luciana Reginato Dias, da secretaria da UFSC - CTJ, que construiu o Quadro 1. Aos professores César Augusto Bortot, Maíra Fernandes Gauer Palma, Rômulo Alberto Castillo Cardenas, Thales Maier de Souza e Victor Simões Barbosa, que têm trabalhado ativamente na construção do evento Maratona de Cálculo. Aos discentes que aceitaram ser entrevistados e gravados para que pudéssemos entender melhor seus pontos de vista sobre a Maratona de Cálculo. Aos avaliadores que fizeram importantes contribuições neste artigo. À Pró-Reitoria de Extensão - PROEX da UFSC, que financiou este projeto nos anos de 2019 e 2020, através do Programa de Bolsas de Extensão - PROBOLSAS.

\section{REFERÊNCIAS}

BARUFI, M. C. B. A Construção/ Negociação de Significados no Curso Universitário Inicial de Cálculo Diferencial e Integral. São Paulo, 1999 - Tese de doutorado.

ELIAS, L. M. Maratona de Cálculo da UFSC Joinville, 2020. Site do projeto Maratona de Cálculo. Disponível em: http://maratonadecalculo.paginas.ufsc.br. Acesso em: 05/08/2020

FRAGELLI, R. Rei da Derivada, 2020. Site do projeto Rei da Derivada. Disponível em: http://www.reidaderivada.com/. Acesso em: 3, março 2020.

GRANDO, R. C. O jogo na educação: aspectos didático-metodológicos do jogo na educação matemática. Unicamp, 2001 apud MOTA, P.C.C.L.M.(2009). Jogos no ensino da Matemática. (Dissertação de Mestrado), Universidade Portucalense, Portugal.

PEREIRA, V. M. C. Cálculo no Ensino Médio: Uma proposta para o problema da variabilidade. Dissertação (Mestrado em Ensino de Matemática) - Instituto de Matemática, Universidade Federal do Rio de Janeiro, Rio de Janeiro, 2009 
Estudo da maratona de cálculo como intervenção para o elevado índice de retenção em Cálculo I

PONTES, P. C.; RIBEIRO, M. S. S.; PEREIRA, M. J; FONSECA, M. C. P.; FONSECA; M. L. P. A Relação do Conhecimento de Cálculo I no Desempenho e Conclusão dos Cursos de Engenharia Um Estudo de Caso no Curso de Alimentos. COBENGE, 2012.

RAFAEL, R. C. Cálculo Diferencial e Integral: um estudo sobre estratégias para redução do percentual de não aprovação. Juiz de Fora (MG); Abril, 2017. Dissertação.

SANTOS, A. P.; RIOS, J.R.T.; NASCIMENTO, C. A Evasão e a Retenção no Ciclo Básico dos Cursos de graduação em Engenharia da Escola de Minas da Universidade Federal de Ouro Preto. 2001. (Apresentação de Trabalho/Congresso).

SANTOS, A. P.; RIOS, J.R.T. ; NASCIMENTO, C. . Estudo da Evasão e da Retenção nos Cursos de graduação em Engenharia da Escola de Minas da Universidade Federal de Ouro Preto. 2000. (Apresentação de Trabalho/Congresso).

Recebido em: 30/03/2021

Aceito em: 02/12/2021 